\title{
The sex difference of plasma homovanillic acid is unaffected by cross-sex hormone administration in transsexual subjects
}

\author{
Erik J Giltay, King H Kho, Ben A Blansjaar, Marcel M Verbeek ${ }^{1}$, \\ P Ben H Geurtz ${ }^{1}$, Johanna M Geleijnse ${ }^{2}$ and Louis J G Gooren ${ }^{3}$ \\ Geestelijke Gezondheidszorg Delfland, Institute of Mental Health, PO Box 5016, 2600 GA Delft, The Netherlands \\ ${ }^{1}$ Radboud University Nijmegen Medical Centre, Department of Neurology, Laboratory of Pediatrics and Neurology, Nijmegen, The Netherlands \\ ${ }^{2}$ Division of Human Nutrition, Wageningen University, Wageningen, The Netherlands \\ ${ }^{3}$ Department of Endocrinology, Andrology Unit, Vrije Universiteit University Medical Center, Amsterdam, The Netherlands \\ (Requests for offprints should be addressed to E J Giltay; Email: giltay@dds.nl)
}

\begin{abstract}
There is a close relationship between the brain and the endocrine system. The brain expresses receptors for sex steroids and is capable of metabolizing these hormones. We explored (1) sex differences in homovanillic acid (HVA), a metabolite of the neurotransmitter dopamine, and (2) the effects of cross-sex steroid administration in transsexual subjects. First, we compared plasma HVA levels between 38 male and 34 female healthy volunteers (not using hormone replacement therapy) of a mean age of 72 years (range 65-84 years). Secondly, we measured plasma HVA levels in 15 male-to-female transsexuals treated with $100 \mu \mathrm{g}$ ethinyl estradiol/day and $100 \mathrm{mg}$ cyproterone acetate/day for 4 months, and in 17 femaleto-male transsexuals treated with testosterone esters (250 mg/2 weeks i.m. for 4 months). Plasma HVA levels were lower in elderly men than in elderly postmenopausal women (geometric mean $25.4 \mathrm{nmol} / 1$ (percentile $(\mathrm{P})_{10}$ 4.9; $\left.\mathrm{P}_{90} 69 \cdot 8\right)$ vs $\left.39 \cdot 0 \mathrm{nmol} / 1(19 \cdot 0 ; 76 \cdot 1) ; P=0 \cdot 027\right)$. In
\end{abstract}

transsexuals before cross-sex hormone administration, genetic males also had lower plasma levels of HVA than genetic females (geometric mean $14 \cdot 8 \mathrm{nmol} / 1\left(\mathrm{P}_{10} 7 \cdot 0 ; \mathrm{P}_{90}\right.$ $35 \cdot 0)$ vs $34 \cdot 3 \mathrm{nmol} / 1(21 \cdot 8 ; 61 \cdot 4) ; P<0 \cdot 001)$. Cross-sex hormone administration did not affect plasma HVA in either group $(P>0 \cdot 5)$. The pretreatment sex difference in plasma HVA was unaffected after 4 months of cross-sex hormone administration $(P=0 \cdot 003)$. The sex difference in plasma HVA was not reversed by cross-sex hormone administration in transsexuals, and was also preserved in elderly subjects. This indicated that differences in dopamine gene expression were largely unaffected by exposure to sex hormone levels in adulthood, but must rather be explained by a sex difference in genetic factors or by the organizing effects of sex hormones during early development.

Journal of Endocrinology (2005) 187, 109-116

\section{Introduction}

Sex differences in schizophrenia, with an earlier onset (Hambrecht et al. 1992, Albus \& Maier 1995, Szymanski et al. 1995, Halbreich \& Kahn 2003) and a higher prevalence (Aleman et al. 2003) in men than in women, may indicate that sex hormones are implicated in its expression, etiology and course. The brain contains receptors (Kruijver et al. 2001, 2003, Toran-Allerand 2004) for androgens and estrogens, and is capable of synthesizing and metabolizing these steroids (Puy et al. 1995, Poletti \& Martini 1999, Stoffel-Wagner 2003, Altman 2004). Dopamine is synthesized from tyrosine by dopaminergic neurons, and is also the precursor to norepinephrine in noradrenergic nerves. Dopamine is metabolized in the brain, liver and kidney to its inactive metabolite homovanillic acid (HVA; Fig. 1), and in human (Amin et al.
1995, Amin et al. 1998) and animal (Bacopoulos et al. 1979) research its plasma concentration was found to be indicative of brain dopamine turnover. Plasma HVA is not only elevated in neuroblastomas and pheochromacytomas, but also in schizotypical personality disorders (Siever et al. 1991). In some (Pickar et al. 1986, Davidson \& Davis 1988, Maas et al. 1988, Davidson et al. 1991, Koreen et al. 1994, Sumiyoshi et al. 1997a) but not all (Sumiyoshi et al. 1997b) studies, the baseline and/or change in plasma HVA was related to psychopathology and treatment response in schizophrenic patients.

Sex steroids have been found to affect neurotransmitters and neurotransmitter receptors of the dopaminergic systems in complex ways, at least in cell and animal studies (Becker 1999, Eaton et al. 1999, Andersen et al. 2002, Landry et al. 2002, Halbreich \& Kahn 2003, D'Astous et al. 2004). In humans, the potential effects of sex 


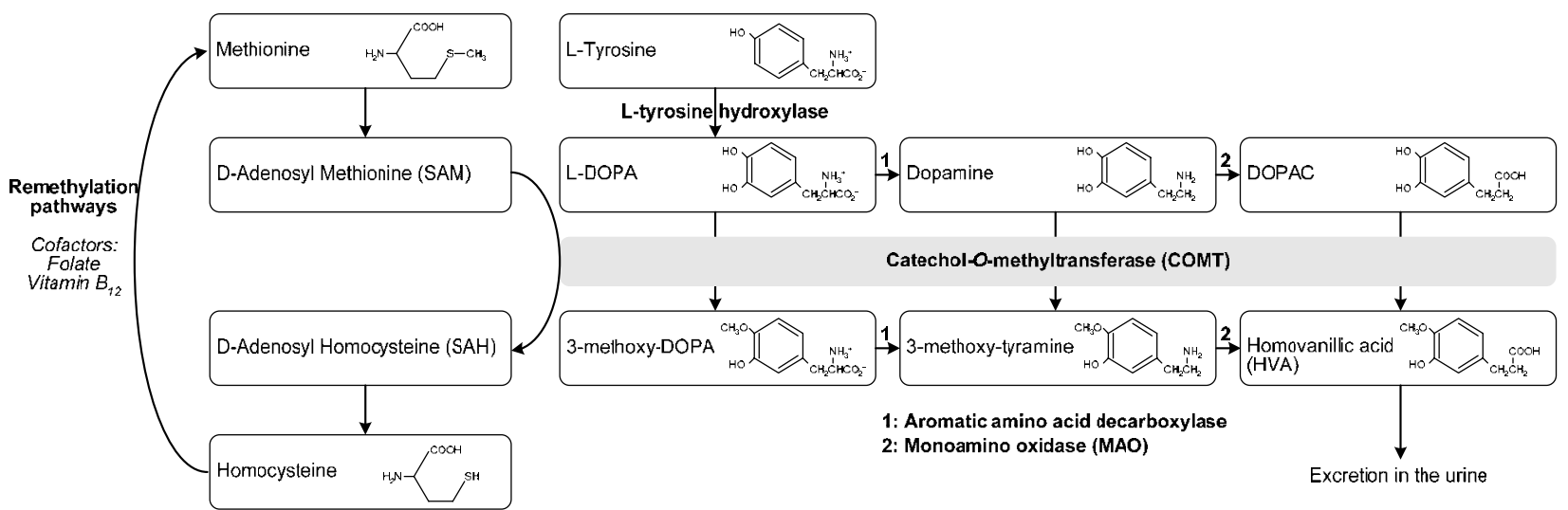

Figure 1 Role of catechol-O-methyltransferase (COMT)-mediated methylation in dopamine metabolism. The major detoxification pathway (i.e. metabolizing dopamine to inactivate metabolites) involves $O$-methylation at the meta-hydroxyl group and oxidative deamination. O-Methylation is catalyzed by the enzyme COMT and oxidative deamination is catalyzed by MOA, primarily MAO B. HVA is the end product of dopamine metabolism and can be used as a marker of dopamine turnover. Methionine forms S-adenosylmethionine (SAM), which serves as the methyl donor to dopamine (and other compounds). Homocysteine, which is formed during this metabolism of methionine, is metabolized back into methionine through one of two remethylation pathways, one of which using folate as a cofactor. DOPA, 3,4-dihydroxyphenylalanine; DOPAC, 3,4-dihydroxyphenylacetic acid.

hormone administration on dopaminergic activity have not yet been studied extensively (Lobo et al. 1984, Hannan et al. 1991, Paoletti et al. 2001). Administration of testosterone, which endogenously is partially aromatized to estrogens, did not affect serum HVA in a small group of men (Hannan et al. 1991), although nandrolone decanoate, only a weakly aromatizable synthetic anabolic steroid, did increase serum HVA. A consistent sex difference has been described for plasma HVA levels. Higher plasma levels of HVA are found in female patients with schizophrenia (Koreen et al. 1994, Davila et al. 1995, Szymanski et al. 1995, Sumiyoshi et al. 1997b), in female patients with psychotic disorders (Bowers et al. 1983, Bowers \& Swigar 1987), in female patients with tardive dyskinesia (Glazer et al. 1983), as well as in healthy female controls (Koreen et al. 1994, Sumiyoshi et al. 1997b) as compared with their male counterparts. This sex difference in plasma HVA implies sex differences in dopamine metabolism but not necessarily in dopamine levels.

Studies in transsexual subjects have shown that cross-sex hormones affect psychological variables of aggression, mood, sexual motivation and sex-related cognitive functions, such as verbal fluency and visuospatial functions (Van Goozen et al. 1995, Slabbekoorn et al. 1999). Studies of the brains of transsexuals have shown that certain sex dimorph areas of the brain have a differentiation of the opposite sex (female in male-to-female transsexuals and vice versa). These anatomical brain structures were not affected by the administration of cross-sex hormones (Zhou et al. 1995, Kruijver et al. 2000). In the present study, we have investigated whether changes in sex hormones affect the sex difference in plasma HVA, to test the hypothesis as to whether human dopamine metabolism is under sex steroidal influence. Blood samples were collected as part of a study on the effects of sex hormones on cardiovascular risk factors (Giltay et al. 2000, 2003). We measured fasting plasma HVA levels because of the better reproducibility and smaller variability as compared with urinary HVA (Donnelly et al. 1996, Amin et al. 1998). It is also a less invasive approach than sequentially obtaining cerebrospinal fluid.

\section{Materials and Methods}

First, the sex difference in HVA and 5-hydroxyindoleacetic acid (5-HIAA) were studied in 38 male and 34 female healthy volunteers of the Arnhem Elderly Study, a population-based cohort study that started in 1991 (Giltay et al. 2004). In total, 641 independently living men and women aged 65-84 years in the city of Arnhem agreed to have a venipuncture. Plasma HVA and 5-HIAA was assessed in a random sample of 72 subjects. None of these postmenopausal women were using hormone replacement therapy. The body mass index (BMI; weight/ height ${ }^{2}$ ) was assessed. All subjects provided written informed consent. The study was approved by the ethical committee of Wageningen University.

Secondly, the effects of cross-sex hormone administration on HVA and 5-HIAA were studied in transsexual subjects in blood samples collected from 1996 to 1998 (Giltay et al. 2000, 2003). Psychological criteria for the diagnosis and treatment followed the guidelines provided by the Harry Benjamin International Gender Dysphoria Association. Fifteen male-to-female $(\mathrm{M} \rightarrow \mathrm{F})$ transsexuals were treated with ethinyl estradiol (Lynoral; $100 \mu \mathrm{g}$ /day; Organon, Oss, The Netherlands) in combination with cyproterone acetate (Androcur; $100 \mathrm{mg}$ /day; Schering, 
Berlin, Germany), an anti-androgen that blocks androgen receptors. Seventeen female-to-male $(\mathrm{F} \rightarrow \mathrm{M})$ transsexuals were treated with testosterone esters (Sustanon; $250 \mathrm{mg} / 2$ weeks i.m.; Organon) according to our standard treatment. To monitor the anabolic/catabolic effects on body composition, the BMI was assessed, and lean body mass and total body fat were estimated using bioelectrical impedance analysis (BIA 101/S; RJL Systems, Clinton Twp, MI, USA). Informed consent was obtained from all subjects, and the study was conducted according to the principles of the Declaration of Helsinki and approved by the Ethical Review Committee of the Vrije Universiteit University Medical Center.

\section{Laboratory tests}

A single non-fasting blood sample was first obtained from elderly subjects. Venipuncture was performed between 0800 and $1730 \mathrm{~h}$ using citrate collection tubes. Samples were stored at $-80{ }^{\circ} \mathrm{C}$, and only thawed once before analysis. Secondly, in transsexual subjects, blood was sampled before and 2 and 4 months after initiation of cross-sex hormone administration. Blood was drawn from genetic women before testosterone treatment between days 5 and 9 of the follicular phase and again during testosterone treatment, within 5 to 9 days after the testosterone injection. All blood was sampled after a 12-h fast, immediately placed on ice, centrifuged at $3500 \mathrm{~g}$ for $30 \mathrm{~min}$ at $4{ }^{\circ} \mathrm{C}$, stored within $1 \mathrm{~h}$ at $-80^{\circ} \mathrm{C}$ and never thawed until analysis. EDTA plasma samples (Becton Dickinson Vacutainer Systems, Franklin Lakes, NJ, USA) were obtained. Serum measurements were made of $17 \beta$ estradiol (by radioimmunoassay; Sorin Biomedica, Saluggia, Italy) and testosterone (by radioimmunoassay; CoatA-Count; Diagnostic Products, Los Angeles, CA, USA), luteinizing hormone ( $\mathrm{LH}$; by immunometric luminescence assay; Amerlite; Amersham Pharmacia Biotech, Aylesbury, Bucks, UK) and follicle-stimulating hormone (FSH; by immunometric luminescence assay; Amerlite). Since estrogens increase the secretion of prolactin by the pituitary gland and prolactin release is tonically inhibited by dopamine, we measured prolactin levels (by immunoradiometric assay; Biosource Technologies, Inc., Fleurus, Belgium). HVA and 5-HIAA are cleared by the kidney so we therefore assessed creatinine levels by using standard laboratory methods. Because HVA is formed in close conjunction with homocysteine synthesis (Fig. 1), we measured plasma levels of total homocysteine and folate by high-performance liquid chromatography (HPLC) as previously published (Giltay et al. 2003). Moreover, folate may also be indirectly involved in rate-limiting enzymes for dopamine and serotonin production through tetrahydrobiopterin (Bottiglieri et al. 2000).

To measure HVA and 5-HIAA, the major metabolite of serotonin, samples were mixed with an equal volume of perchloric acid (1 M) in order to precipitate proteins. After centrifugation, the supernatant $(250 \mu \mathrm{l})$ was loaded on a Hypersil ODS HPLC column (Thermo Electron Corporation, Breda, The Netherlands) at $30^{\circ} \mathrm{C}$. The mobile phase consisted of ammonium acetate $(0 \cdot 02 \mathrm{M})$, sodiumEDTA $(0.25 \mathrm{mM})$, sodium chloride $(6.5 \mathrm{mM})$ and methanol $(9 \cdot 5 \%)$ at $\mathrm{pH} 4.95$. The flow was set at $1.25 \mathrm{ml} / \mathrm{min}$ by using an isocratic Sp8810 pump (Thermo Electron Corporation). Detection was performed by using an electrochemical detector (INTRO; Antec Leyden, Zoeterwoude, The Netherlands; potential: $0.525 \mathrm{mV}$ ). Chromatographic data were recorded by using PC1000 software (Thermo Electron Corporation). The intra-assay coefficient of variation (C.V.) for HVA was $2 \cdot 0 \%$ at a concentration of $156 \mathrm{nM}(n=9)$ and interassay C.V. was $2 \cdot 7 \%$ at a concentration of $160 \mathrm{nM}(n=7)$. The intra-assay C.V. for 5-HIAA was $3 \cdot 8 \%$ at a concentration of $93 \mathrm{nM}$ $(n=9)$ and the interassay C.V. was $5 \cdot 5 \%$ at a concentration of $55 \mathrm{nM}(n=7)$.

\section{Statistical analysis}

Data are presented as means (with S.D.) or geometric means (with percentiles: $\mathrm{P}_{10}$ and $\mathrm{P}_{90}$ ) for right-skewed data (i.e. total homocysteine, folate and HVA). HVA and 5-HIAA values were correlated with other variables using Spearman's correlation coefficient. For the comparison at baseline between the two groups, a $t$-test for independent samples or analysis of covariance was used. For $\mathrm{M} \rightarrow \mathrm{F}$ transsexuals, a two-factor repeated measures ANOVA with interaction was used to study the effects of estrogens plus anti-androgens in time, as well as to compare the effects of the two treatment regimens in time. Post-hoc comparisons were made using a Sidak test to identify significant differences between time-points. For $\mathrm{F} \rightarrow \mathrm{M}$ transsexuals, a Student's $t$-test for paired samples was used to study the effects of androgen administration in time. A two-tailed $P<0 \cdot 05$ was considered statistically significant. The software used was SPSS 10·0, Chicago, IL, USA.

\section{Results}

\section{Comparison between elderly men and women}

Men were, on average, 72.5 years old (S.D. 4.9 ; range 65-84) and women were $72 \cdot 8$ years old (S.D. 5.8; range 65-83; for sex difference $P=0 \cdot 79$ ). The BMI was a mean of $24 \cdot 6$ (s.D. 3.0) in men and $26 \cdot 1$ (s.D. $5 \cdot 0$ ) in women (for sex difference $P=0 \cdot 15)$. Plasma HVA levels were lower in elderly men than postmenopausal women (geometric mean $25.4 \mathrm{nmol} / 1\left(\mathrm{P}_{10} 4 \cdot 9 ; \mathrm{P}_{90} 69 \cdot 8\right)$ vs $39 \cdot 0 \mathrm{nmol} / 1$ (19.0; 76.1); $P=0 \cdot 027)$. Plasma HVA was positively associated with age $(r=0.26, P=0.026)$. The sex difference for plasma HVA remained present after adjusting for age $(P=0 \cdot 033)$. Plasma 5-HIAA levels were similar in elderly men and women $(P=0.42)$, also when one outlier $(323 \mathrm{nmol} / \mathrm{l})$ was excluded from the analysis $(21.6 \mathrm{nmol} / \mathrm{l}$ (S.D. $15 \cdot 3$ ) vs $21 \cdot 9 \mathrm{nmol} / 1$ (S.D. $24 \cdot 6$ ); $P=0 \cdot 94$ ). 

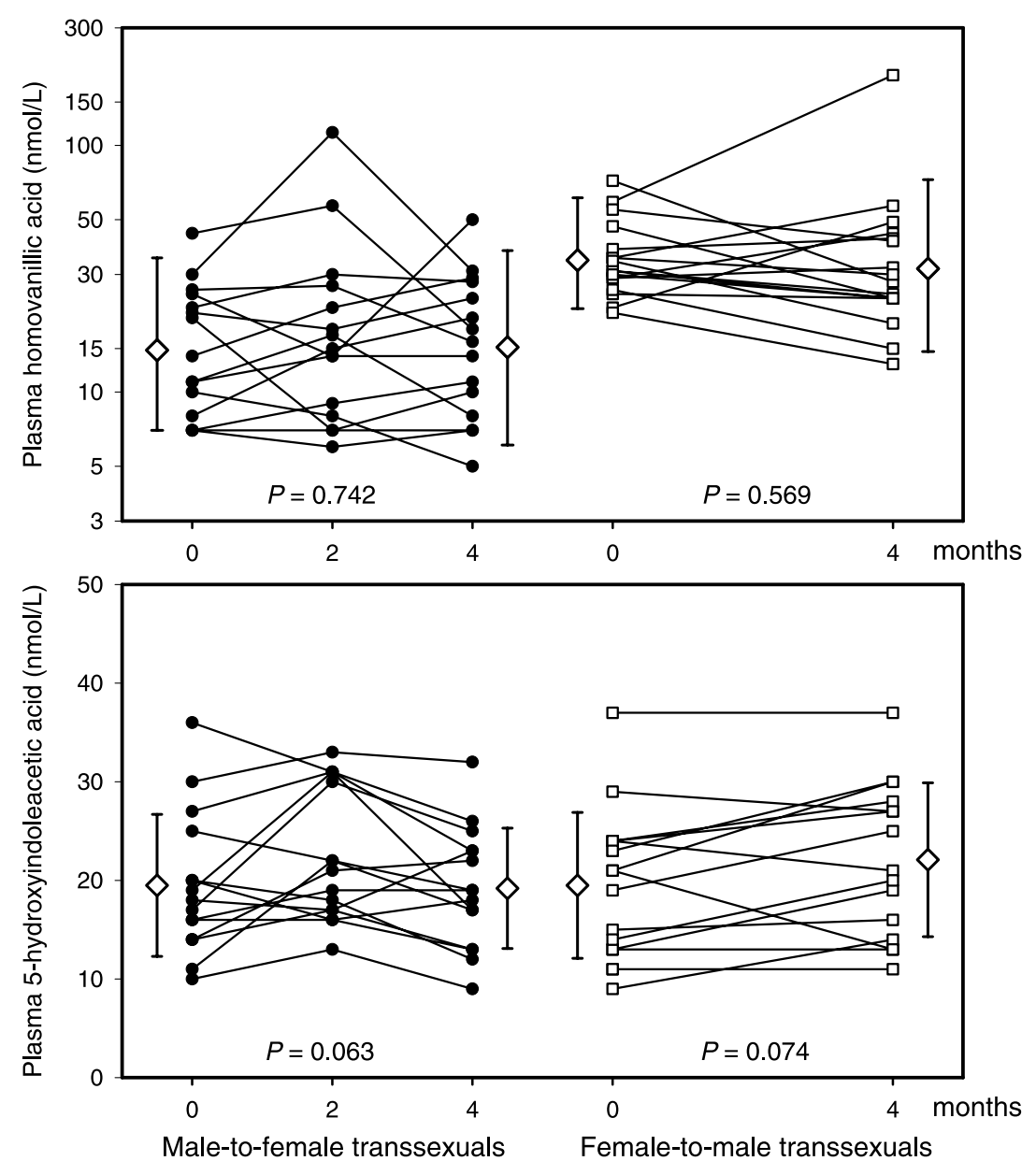

Figure 2 Individual values of HVA on a logarithmic scale and 5-HIAA in $15 \mathrm{M} \rightarrow \mathrm{F}$ transsexuals $(-$ at baseline and after 2 and 4 months of administration of ethinyl estradiol plus cyproterone acetate and $17 \mathrm{~F} \rightarrow \mathrm{M}$ transsexuals $(\square)$ at baseline and after 4 months of administration of testosterone esters. Back-transformed mean values (with confidence intervals) at 0 and 4 months are identified by diamonds. $P$ values were assessed by ANOVA for repeated measurements for $M \rightarrow F$ transsexuals and by $t$-test for paired samples for $F \rightarrow M$ transsexuals. At baseline, sex differences were statistically significant for plasma HVA $(P<0.0005)$ and not for 5-HIAA $(P=0.981)$. At 4 months, the sex difference remained statistically significant for plasma HVA $(P=0.003)$.

Intervention studies with sex steroids

Pretreatment values The mean age of $\mathrm{M} \rightarrow \mathrm{F}$ transsexuals was $32 \cdot 4$ (S.D. 6.6; range 20-43) years with a BMI of $22 \cdot 8$ (S.D. $2 \cdot 7$ ) $\mathrm{kg} / \mathrm{m}^{2}$ and that of $\mathrm{F} \rightarrow \mathrm{M}$ transsexuals was $27 \cdot 1$ (S.D. $6 \cdot 3$; range $18-37$ ) years with a BMI of $23 \cdot 9$ (S.D. $4 \cdot 3) \mathrm{kg} / \mathrm{m}^{2}$. Of the $\mathrm{M} \rightarrow \mathrm{F}$ transsexuals, nine $(60 \%)$ were smokers and of the $\mathrm{F} \rightarrow \mathrm{M}$ transsexuals ten $(59 \%)$ were smokers.

In $\mathrm{M} \rightarrow \mathrm{F}$ transsexuals, baseline HVA levels were inversely associated with testosterone levels $(r=-0 \cdot 61$, $P=0 \cdot 017)$ and LH levels $(r=-0 \cdot 70, P=0 \cdot 003)$, whereas baseline 5-HIAA levels were positively associated with creatinine levels $(r=0.53, \quad P=0 \cdot 050)$. Smokers had significantly lower HVA levels as compared with non-smokers $(P=0.003)$, and similar levels of 5-HIAA $(P=0.18)$. In $\mathrm{F} \rightarrow \mathrm{M}$ transsexuals, baseline HVA and 5-HIAA levels were not correlated with levels of hormones, creatinine or folate, and baseline HVA levels were not correlated with levels of total homocysteine. Smokers had similar levels of HVA and 5-HIAA as compared with non-smokers $(P=0.50$ and $P=0.54$ respectively). Age was unrelated to plasma HVA or 5 -HIAA in either group $(P>0 \cdot 20)$.

At baseline, plasma HVA was significantly lower in genetic men as compared with women (geometric mean $14.8 \mathrm{nmol} / 1\left(\mathrm{P}_{10} 7 \cdot 0 ; \mathrm{P}_{90} 35 \cdot 0\right)$ vs $34.3\left(\mathrm{P}_{10} 21 \cdot 8 ; \mathrm{P}_{90}\right.$ 61.4); $P<0 \cdot 0005$; Fig. 2 and Table 1). The sex difference remained present $(P=0.003)$ after adjusting for age, 


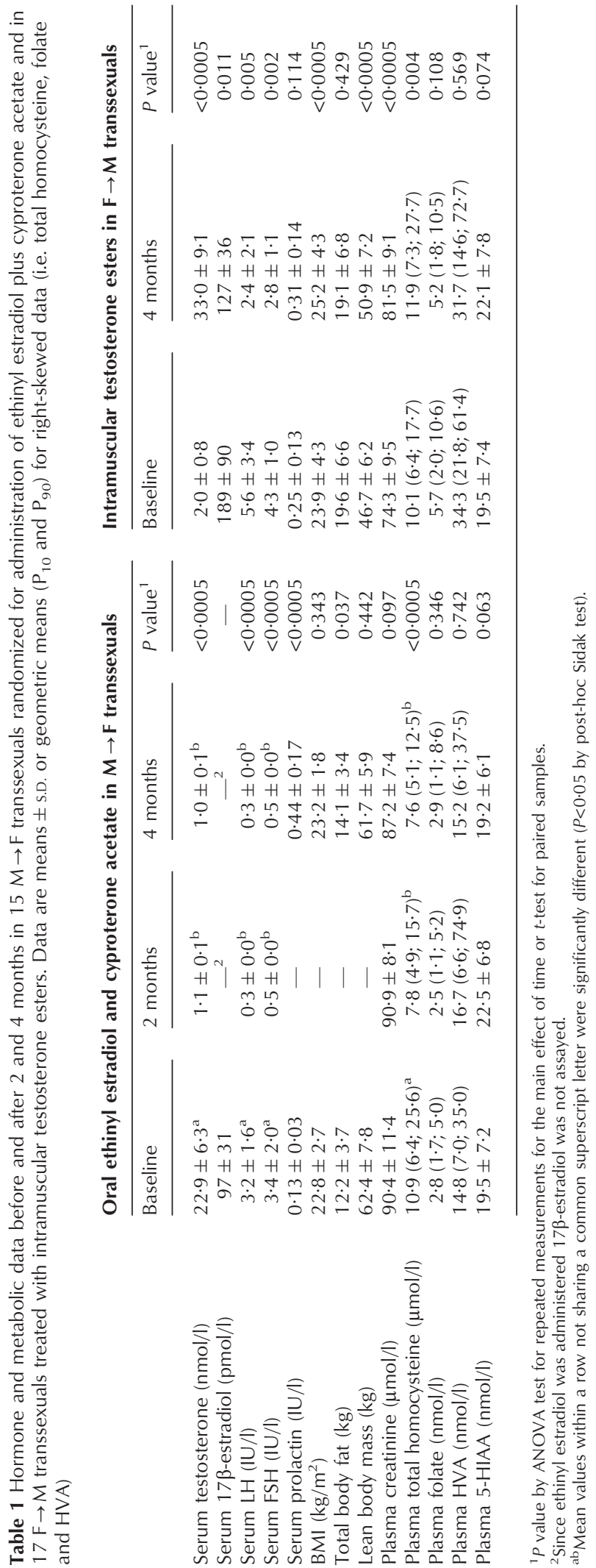

smoking status, BMI and creatinine levels as covariates. No sex difference was found for 5-HIAA ( $P=0.981$; Fig. 2 and Table 1).

Effects of cross-sex hormone administration In $\mathrm{M} \rightarrow \mathrm{F}$ transsexuals, estrogen administration substantially decreased serum levels of testosterone, $\mathrm{LH}$ and $\mathrm{FSH}$, whereas prolactin levels increased. The synthetic estrogen, ethinyl estradiol, could not be detected by the $17 \beta$ estradiol assay used (Table 1). There were no significant effects on plasma HVA and 5-HIAA (Fig. 2 and Table 1), although the change in plasma 5-HIAA was of borderline significance $(P<0 \cdot 10)$, though quantitatively small. The proportional increase in prolactin or decrease in testosterone, LH, FSH and total homocysteine were not related to proportional changes in plasma HVA or 5-HIAA.

In $\mathrm{F} \rightarrow \mathrm{M}$ transsexuals, testosterone administration increased serum levels of testosterone and creatinine levels, while serum levels of $17 \beta$-estradiol, LH and FSH were suppressed. Partly reflecting the anabolic effects, there were increases in BMI, lean body mass and plasma creatinine and homocysteine. Again, there were no significant effects on plasma HVA and 5-HIAA (Fig. 2), although there was a tendency for plasma 5-HIAA to increase of borderline significance $(P=0 \cdot 074$; Table 1$)$. The proportional changes in hormones, total homocysteine and creatinine were not related to the proportional changes in plasma HVA or 5-HIAA.

When baseline and 4-month values were used, there was no treatment effect when the two groups were combined in an ANOVA for repeated measurements, either for HVA $(P=0 \cdot 79)$ or for 5-HIAA $(P=0 \cdot 21)$. Thus, the effects of estrogen plus anti-androgen administration were not significantly different from the effects of testosterone administration. After 2 and 4 months of estrogen plus anti-androgen administration, smoking $M \rightarrow F$ transsexuals still had lower plasma HVA levels as compared with non-smoking $\mathrm{M} \rightarrow \mathrm{F}$ transsexuals $(P<0 \cdot 01)$. After 4 months of cross-sex hormone administration, there was still a lower mean level of plasma HVA in $\mathrm{M} \rightarrow \mathrm{F}$ transsexuals (genetic men) as compared with $\mathrm{F} \rightarrow \mathrm{M}$ transsexuals (genetic women) $\left(15 \cdot 2 \mathrm{nmol} / 1\left(\mathrm{P}_{10} 6 \cdot 1 ; \mathrm{P}_{90} 37 \cdot 5\right)\right.$ vs $31 \cdot 7$ $\left(\mathrm{P}_{10}\right.$ 14.6; $\mathrm{P}_{90}$ 72.7); $P=0 \cdot 003$; Fig. 2 and Table 1$)$.

\section{Discussion}

Subjects in our study were (1) elderly men and postmenopausal women and (2) adult eugonadal genetic male and female transsexuals with sex-appropriate levels of sex steroids. In previous studies, women were found to have higher plasma levels of HVA than men (Bowers et al. 1983, Glazer et al. 1983, Bowers \& Swigar 1987, Koreen et al. 1994, Davila et al. 1995, Szymanski et al. 1995, Sumiyoshi et al. 1997b), which could hypothetically be ascribed to their respective differences in sex steroid 
milieus. However, this idea is not supported by our data. First, HVA levels in plasma were lower in elderly men than in postmenopausal women. This suggested that the sex difference is not affected by the decline in sex steroid levels as the physiological manifestations of aging, particularly following menopause. Remarkably enough, aging men have higher circulating levels of estradiol than postmenopausal women (Vermeulen et al. 2002). Secondly, administration of a high dose of oral ethinyl estradiol plus cyproterone acetate to genetic men and of testosterone to genetic women did not affect plasma HVA. Therefore, the male/female difference in plasma HVA cannot be explained by the male/female difference in sex steroid milieus, although an inverse correlation between HVA and testosterone levels was found in the genetic male group at baseline. These results are in line with the findings that testosterone administration in healthy young men did not affect HVA levels (Hannan et al. 1991), that women with polycystic ovary syndrome, which is associated with hyperandrogenism, have similar plasma levels of catecholamines and urinary levels of HVA as compared with female controls (Garcia-Rudaz et al. 1998), and that estrogen administration to postmenopausal women did not affect urinary HVA levels (Lobo et al. 1984).

What mechanism may explain the sex difference in HVA? Since sex steroids did not affect HVA, a putative explanation may be a sex differences in gene expression. MAO A and especially MAO B are responsible for the oxidative deamination of dopamine (Fig. 1), and are both coded for on the X chromosome (i.e. Xp11 region). There is evidence that MAO A and especially MAO B escape $\mathrm{X}$-chromosome inactivation (Good et al. 2003). Since (genetic) women have two $\mathrm{X}$ chromosomes and MAO may be expressed from both $\mathrm{X}$ chromosomes, this would result in higher MAO activity and consequently higher HVA levels in women then in men. Alternatively, there are sex differences in the brain which develop and mature until early adulthood (Gogtay et al. 2004) and sex steroids may have produced lasting, so-called organizational, effects on dopamine-producing tissue during fetal, perinatal and pubertal periods. Previous studies in transsexuals also suggest that sexually dimorphic brain structures are resistant to exposure to cross-sex hormones and are not influenced by gonadal steroids during adulthood, but they have rather originated by direct action of the genetic factors (e.g. difference in gene dosage) or by the organizational effects of gonadal steroids during early development (Zhou et al. 1995, Kruijver et al. 2000).

We found that $\mathrm{M} \rightarrow \mathrm{F}$ transsexuals who were smokers had significantly lower plasma HVA as compared with non-smokers, which is in accordance with the finding that male smokers had lower cerebrospinal fluid levels of HVA (Geracioti et al. 1999). Cigarette smoke may have substantially inhibited the central nervous system MOA activity, leading to increased dopaminergic activity (Fig. 1) (Brody et al. 2004) as well as lower plasma HVA. Alternatively, men with low HVA levels may be more prone to become smokers (i.e. reverse causation). The increase in prolactin levels in $\mathrm{M} \rightarrow \mathrm{F}$ transsexuals upon estrogen administration is likely the reflection of a direct estrogenic enhancement or lower dopaminergic inhibitory effects on prolactin secretion. In previous studies in postmenopausal women, estrogen replacement therapy increased prolactin and cortisol responses to the serotonin agonist metachlorophenylpiperazine (Halbreich et al. 1995) and hormone replacement therapy increased prolactin secretion in response to the dopamine-blocking agent sulpiride (Paoletti et al. 2001). The findings were thought to reflect changes in serotonergic and dopaminergic activity upon estrogen administration (Halbreich et al. 1995, Paoletti et al. 2001). These estrogenic effects may be confined to the pituitary gland and the hypothalamic structures that control the pituitary production of prolactin, but the effects of sex hormones are likely to differ from one brain region to another. Dopamine degradation proceeds by MOA and COMT, which catalyze the transfer of a methyl group from methionine to dopamine, resulting in homocysteine and HVA (Fig. 1). Because the synthetic pathways are coupled, it is of note that the profound decrease and increase in plasma total homocysteine in $\mathrm{M} \rightarrow \mathrm{F}$ and $\mathrm{F} \rightarrow \mathrm{M}$ transsexuals respectively (Giltay et al. 2003) were not paralleled by changes in plasma HVA.

Methodologically, the use of plasma levels of HVA has its limitations. Plasma levels of HVA are dependent upon the balance between both delivery into the plasma and clearance from the plasma (half-life: $\pm 40 \mathrm{~min}$ ) (Goldstein et al. 2003). Only 12-40\% of HVA in plasma is of central nervous system origin (Swann et al. 1980, Maas et al. 1988, Lambert et al. 1991, Lambert et al. 1993, Amin et al. 1995, 1998); much more is derived from central and peripheral sympathetic nerves and the adrenal medulla. It is possible that sex steroids affected biosynthesis, transport, concentration, uptake, receptor potentiation and density, postsynaptic responsivity, blood-brain barrier, degradation, or clearance of dopamine and serotonin (Halbreich \& Kahn 2001). Potential effects on dopamine and serotonin activity may have been obscured by compensatory (i.e. negative feedback) mechanisms, and by the indirect assessment of monoamine status in plasma samples. Finally, alterations in renal clearance may cause concomitant changes in the plasma HVA. However, the increase in plasma creatinine upon testosterone administration is not caused by a decrease in renal function, since creatinine clearance was unaffected by testosterone administration in another study of cross-sex hormone administration to transsexuals (Giltay et al. 1998). The increase in plasma creatinine is rather a reflection of the anabolic effect of testosterone in genetic females, as indicated by the increase in lean body mass.

The interpretation of our results is limited by the inclusion of a relatively small numbers of subjects. Furthermore, the intervention study had a relatively short follow-up of 4 months, had an open-label design and 
lacked a true placebo group, due to the nature of the study population and the treatment indication. Moreover, different effects may have been found in hypogonadal men and women undergoing sex-appropriate hormone replacement. Yet, the dose of cross-sex hormone administration was high and the levels of HVA were consistently lower in men than in women as well as in $\mathrm{M} \rightarrow \mathrm{F}$ transsexuals than in $\mathrm{F} \rightarrow \mathrm{M}$ transsexuals, both before and after cross-sex hormone administration.

We found that fasting plasma levels of HVA, the major metabolites of dopamine, was not significantly changed by administration of high-dose cross-sex hormone administration in $\mathrm{F} \rightarrow \mathrm{M}$ and $\mathrm{M} \rightarrow \mathrm{F}$ transsexual subjects. Our results have suggested that the sex difference in plasma HVA - with higher HVA levels in females than in males - is related to mechanisms other than exposure to sex steroids in adulthood, and may rather be the result of a sex difference in genetic factors or of organizing effects of sex hormones during early development.

\section{Acknowledgements}

The authors declare that there is no conflict of interest that would prejudice the impartiality of this scientific work.

\section{References}

Albus M \& Maier W 1995 Lack of gender differences in age at onset in familial schizophrenia. Schizophrenia Research 18 51-57.

Aleman A, Kahn RS \& Selten JP 2003 Sex differences in the risk of schizophrenia: evidence from meta-analysis. Archives of General Psychiatry 60 565-571.

Altman J 2004 Gonadal hormones humour the brain. Neuroendocrinology 79 287-295.

Amin F, Davidson M, Kahn RS, Schmeidler J, Stern R, Knott PJ \& Apter S 1995 Assessment of the central dopaminergic index of plasma HVA in schizophrenia. Schizophrenia Bulletin 21 53-66.

Amin F, Stroe AE, Kahn T, Knott PJ, Kahn RS \& Davidson M 1998 Control of renal factors in plasma homovanillic acid measurements. Neuropsychopharmacology 18 317-320.

Andersen SL, Thompson AP, Krenzel E \& Teicher MH 2002 Pubertal changes in gonadal hormones do not underlie adolescent dopamine receptor overproduction. Psychoneuroendocrinology 27 683-691.

Bacopoulos NG, Hattox SE \& Roth RH 1979

3,4-Dihydroxyphenylacetic acid and homovanillic acid in rat plasma: possible indicators of central dopaminergic activity. European Journal of Pharmacology 56 225-236.

Becker JB 1999 Gender differences in dopaminergic function in striatum and nucleus accumbens. Pharmacology, Biochemistry, and Behavior 64 803-812.

Bottiglieri T, Laundy M, Crellin R, Toone BK, Carney MW \& Reynolds EH 2000 Homocysteine, folate, methylation, and monoamine metabolism in depression. Journal of Neurology, Neurosurgery, and Psychiatry $69228-232$.

Bowers MB Jr \& Swigar ME 1987 Acute psychosis and plasma catecholamine metabolites. Archives of General Psychiatry 44190.

Bowers MB Jr, Swigar ME \& Jatlow PI 1983 Sex differences in plasma homovanillic acid in acute psychosis. New England Journal of Medicine 308 845-846.
Brody AL, Olmstead RE, London ED, Farahi J, Meyer JH, Grossman P, Lee GS, Huang J, Hahn EL \& Mandelkern MA 2004 Smoking-induced ventral striatum dopamine release. American Journal of Psychiatry 161 1211-1218.

D’Astous M, Gajjar TM, Dluzen DE \& Di Paolo T 2004 Dopamine transporter as a marker of neuroprotection in methamphetamine-lesioned mice treated acutely with estradiol. Neuroendocrinology 79 296-304.

Davidson M \& Davis KL 1988 A comparison of plasma homovanillic acid concentrations in schizophrenic patients and normal controls. Archives of General Psychiatry 45 561-563.

Davidson M, Kahn RS, Knott P, Kaminsky R, Cooper M, DuMont K, Apter S \& Davis KL 1991 Effects of neuroleptic treatment on symptoms of schizophrenia and plasma homovanillic acid concentrations. Archives of General Psychiatry 48 910-913.

Davila R, Gonzalez MA, Zumarraga M, Andia I, Guimon J, Silva RR \& Friedhoff AJ 1995 Plasma prolactin and plasma homovanillic acid: predictors of clinical response in schizophrenia. Biological Psychiatry 38 267-269.

Donnelly CL, McEvoy JP, Wilson WH \& Narasimhachari N 1996 A study of the potential confounding effects of diet, caffeine, nicotine and lorazepam on the stability of plasma and urinary homovanillic acid levels in patients with schizophrenia. Biological Psychiatry 40 1218-1221.

Eaton GG, Worlein JM, Kelley ST, Vijayaraghavan S, Hess DL, Axthelm MK \& Bethea CL 1999 Self-injurious behavior is decreased by cyproterone acetate in adult male rhesus (Macaca mulatta). Hormones and Behavior 35 195-203.

Garcia-Rudaz C, Armando I, Levin G, Escobar ME \& Barontini M 1998 Peripheral catecholamine alterations in adolescents with polycystic ovary syndrome. Clinical Endocrinology 49 221-228.

Geracioti TD Jr, West SA, Baker DG, Hill KK, Ekhator NN, Wortman MD, Keck PE Jr \& Norman AB 1999 Low CSF concentration of a dopamine metabolite in tobacco smokers. American Journal of Psychiatry 156 130-132.

Giltay EJ, Hoogeveen EK, Elbers JMH, Gooren LJG, Asscheman H \& Stehouwer CDA 1998 Effects of sex steroids on plasma total homocysteine levels: a study in transsexual males and females. Journal of Clinical Endocrinology and Metabolism 83 550-553.

Giltay EJ, Gooren LJG, Emeis J, Kooistra T \& Stehouwer CDA 2000 Oral, but not transdermal, administration of estrogens lowers tissue-type plasminogen activator levels without affecting its endothelial synthesis. Arteriosclerosis, Thrombosis, and Vascular Biology 20 1396-1403.

Giltay EJ, Verhoef P, Gooren LJ, Geleijnse JM, Schouten EG \& Stehouwer CD 2003 Oral and transdermal estrogens both lower plasma total homocysteine in male-to-female transsexuals. Atherosclerosis 168 139-146.

Giltay EJ, Geleijnse JM, Zitman FG, Hoekstra T \& Schouten EG 2004 Dispositional optimism and all-cause and cardiovascular mortality in a prospective cohort of elderly Dutch men and women. Archives of General Psychiatry 61 1126-1135.

Glazer WM, Naftolin F, Moore DC, Bowers MB \& MacLusky NJ 1983 The relationship of circulating estradiol to tardive dyskinesia in men and postmenopausal women. Psychoneuroendocrinology 8 429-434.

Gogtay N, Giedd JN, Lusk L, Hayashi KM, Greenstein D, Vaituzis AC, Nugent TF 3rd, Herman DH, Clasen LS, Toga AW, Rapoport JL \& Thompson PM 2004 Dynamic mapping of human cortical development during childhood through early adulthood. PNAS 101 8174-8179.

Goldstein DS, Eisenhofer G \& Kopin IJ 2003 Sources and significance of plasma levels of catechols and their metabolites in humans. Journal of Pharmacology and Experimental Therapeutics 305 800-811.

Good CD, Lawrence K, Thomas NS, Price CJ, Ashburner J, Friston KJ, Frackowiak RS, Oreland L \& Skuse DH 2003 Dosage-sensitive 
$\mathrm{X}$-linked locus influences the development of amygdala and orbitofrontal cortex, and fear recognition in humans. Brain 126 2431-2446.

Halbreich U \& Kahn LS 2001 Role of estrogen in the aetiology and treatment of mood disorders. CNS Drugs 15 797-817.

Halbreich U \& Kahn LS 2003 Hormonal aspects of schizophrenias: an overview. Psychoneuroendocrinology 28 (Suppl 2) 1-16.

Halbreich U, Rojansky N, Palter S, Tworek H, Hissin P \& Wang K 1995 Estrogen augments serotonergic activity in postmenopausal women. Biological Psychiatry 37 434-441.

Hambrecht M, Maurer K \& Hafner H 1992 Gender differences in schizophrenia in three cultures. Results of the WHO collaborative study on psychiatric disability. Social Psychiatry and Psychiatric Epidemiology 27 117-121.

Hannan CJ Jr, Friedl KE, Zold A, Kettler TM \& Plymate SR 1991 Psychological and serum homovanillic acid changes in men administered androgenic steroids. Psychoneuroendocrinology 16 335-343.

Koreen AR, Lieberman J, Alvir J, Mayerhoff D, Loebel A, Chakos M, Amin F \& Cooper T 1994 Plasma homovanillic acid levels in first-episode schizophrenia. Psychopathology and treatment response. Archives of General Psychiatry 51 132-138.

Kruijver FP, Zhou JN, Pool CW, Hofman MA, Gooren LJ \& Swaab DF 2000 Male-to-female transsexuals have female neuron numbers in a limbic nucleus. Journal of Clinical Endocrinology and Metabolism 85 2034-2041.

Kruijver FP, Fernandez-Guasti A, Fodor M, Kraan EM \& Swaab DF 2001 Sex differences in androgen receptors of the human mamillary bodies are related to endocrine status rather than to sexual orientation or transsexuality. Journal of Clinical Endocrinology and Metabolism 86 818-827.

Kruijver FP, Balesar R, Espila AM, Unmehopa UA \& Swaab DF 2003 Estrogen-receptor-beta distribution in the human hypothalamus: similarities and differences with ER alpha distribution. Journal of Comparative Neurology 466 251-277.

Lambert GW, Eisenhofer G, Cox HS, Horne M, Kalff V, Kelly M, Jennings GL \& Esler MD 1991 Direct determination of homovanillic acid release from the human brain, an indicator of central dopaminergic activity. Life Sciences 49 1061-1072.

Lambert GW, Eisenhofer G, Jennings GL \& Esler MD 1993 Regional homovanillic acid production in humans. Life Sciences 53 63-75.

Landry M, Levesque D \& Di Paolo T 2002 Estrogenic properties of raloxifene, but not tamoxifen, on D2 and D3 dopamine receptors in the rat forebrain. Neuroendocrinology 76 214-222.

Lobo RA, Shoupe D, Roy S \& Paul W 1984 Central and peripheral metabolites of norepinephrine and dopamine in postmenopausal women. American Journal of Obstetrics and Gynecology 149 548-552.

Maas JW, Contreras SA, Seleshi E \& Bowden CL 1988 Dopamine metabolism and disposition in schizophrenic patients. Studies using debrisoquin. Archives of General Psychiatry 45 553-559.

Paoletti AM, Floris S, Mannias M, Orru M, Crippa D, Orlandi R, Del Zompo MM \& Melis GB 2001 Evidence that cyproterone acetate improves psychological symptoms and enhances the activity of the dopaminergic system in postmenopause. Journal of Clinical Endocrinology and Metabolism 86 608-612.

Pickar D, Labarca R, Doran AR, Wolkowitz OM, Roy A, Breier A, Linnoila M \& Paul SM 1986 Longitudinal measurement of plasma homovanillic acid levels in schizophrenic patients. Correlation with psychosis and response to neuroleptic treatment. Archives of General Psychiatry 43 669-676.

Poletti A \& Martini L 1999 Androgen-activating enzymes in the central nervous system. Journal of Steroid Biochemistry and Molecular Biology 69 117-122.

Puy L, MacLusky NJ, Becker L, Karsan N, Trachtenberg J \& Brown TJ 1995 Immunocytochemical detection of androgen receptor in human temporal cortex characterization and application of polyclonal androgen receptor antibodies in frozen and paraffin-embedded tissues. Journal of Steroid Biochemistry and Molecular Biology 55 197-209.

Siever LJ, Amin F, Coccaro EF, Bernstein D, Kavoussi RJ, Kalus O, Horvath TB, Warne P, Davidson M \& Davis KL 1991 Plasma homovanillic acid in schizotypal personality disorder. American Journal of Psychiatry 148 1246-1248.

Slabbekoorn D, van Goozen SH, Megens J, Gooren LJ \& Cohen-Kettenis PT 1999 Activating effects of cross-sex hormones on cognitive functioning: a study of short-term and long-term hormone effects in transsexuals. Psychoneuroendocrinology 24 423-447.

Stoffel-Wagner B 2003 Neurosteroid biosynthesis in the human brain and its clinical implications. Annals of the New York Academy of Sciences 1007 64-78

Sumiyoshi T, Hasegawa M, Jayathilake K \& Meltzer HY 1997a Prediction of short-term changes in symptom severity by baseline plasma homovanillic acid levels in schizophrenic patients receiving clozapine. Psychiatry Research 69 113-121.

Sumiyoshi T, Hasegawa M, Jayathilake K \& Meltzer HY 1997b Sex differences in plasma homovanillic acid levels in schizophrenia and normal controls: relation to neuroleptic resistance. Biological Psychiatry 41 560-566.

Swann AC, Maas JW, Hattox SE \& Landis H 1980 Catecholamine metabolites in human plasma as indices of brain function: effects of debrisoquin. Life Sciences 27 1857-1862.

Szymanski S, Lieberman JA, Alvir JM, Mayerhoff D, Loebel A, Geisler S, Chakos M, Koreen A, Jody D \& Kane J 1995 Gender differences in onset of illness, treatment response, course, and biologic indexes in first-episode schizophrenic patients. American Journal of Psychiatry 152 698-703.

Toran-Allerand CD 2004 Minireview: A plethora of estrogen receptors in the brain: where will it end? Endocrinology 145 1069-1074.

Van Goozen SH, Cohen-Kettenis PT, Gooren LJ, Frijda NH \& Van de Poll NE 1995 Gender differences in behaviour: activating effects of cross-sex hormones. Psychoneuroendocrinology 20 343-363.

Vermeulen A, Kaufman JM, Goemaere S \& van Pottelberg I 2002 Estradiol in elderly men. Aging Male 5 98-102.

Zhou JN, Hofman MA, Gooren LJ \& Swaab DF 1995 A sex difference in the human brain and its relation to transsexuality. Nature 378 68-70.

Received 7 July 2005

Accepted 18 July 2005

Made available online as an Accepted Preprint 2 August 2005 